\title{
Cytological analysis of tracheal wash and bronchoalveolar lavage fluid in health and respiratory disease in dromedary camels
}

\author{
Turke Shawaf $^{\text {Corresp., } 1}$, Abdullah Almubarak ${ }^{2}$, Naser Alhumam ${ }^{2}$, Faisal Almathen ${ }^{3,4}$, Jamal Hussen ${ }^{2}$ \\ ${ }^{1}$ Department of Clinical Sciences, College of Veterinary Medicine, King Faisal University, Al-Ahsa, Saudi Arabia \\ 2 Department of Microbiology, College of Veterinary Medicine, King Faisal University, Al-Ahsa, Saudi Arabia \\ 3 Department of Public Health, College of Veterinary Medicine, King Faisal University, Al-Ahsa, Saudi Arabia \\ ${ }^{4}$ The Camel Research Center, King Faisal University, Al-Ahsa, Saudi Arabia \\ Corresponding Author: Turke Shawaf \\ Email address: tshawaf@kfu.edu.sa
}

Background. Tracheal wash (TW) and bronchoalveolar lavage (BAL) have proven to be useful tools for the identification of disease-associated changes in the respiratory tract in human and different animal species. In the dromedary camel, little is known about cytological analysis of TW and BAL in health and disease. The aim of the present study was to evaluate the cytological composition of TW and BAL in health and respiratory disease in dromedary camels. Methods. TW and BAL samples were collected from dromedary camels and cytological analysis was performed by microscopic examination of prepared smears. Camels with clinical respiratory disease $(n=18)$ were compared with apparently healthy (control) camels $(n=9)$. Results. In the apparently healthy camels, differential cytological analysis of TW samples identified macrophages and neutrophils as the main cell populations with lesser proportions of lymphocytes and epithelial cells and very rare abundance of eosinophils and mast cells. In the TW of camels with respiratory disease, neutrophils were the most abundant cells followed by macrophages and lymphocytes. In the BAL of healthy camels, macrophages represented the main cell type followed by lymphocytes and neutrophils. In respiratory-diseased camels, BAL samples contained higher percentages of neutrophils with reduced percentages of macrophages and lymphocytes in comparison to camels from the control group. Collectively, the results of the current study revealed higher abundance of neutrophils in the TW and BAL from dromedary camels than many other veterinary species. The cytological patterns of TW and BAL from camels with respiratory diseases were characterized by increased proportion of neutrophils and decreased proportion of macrophages in comparison to healthy camels. The proportion of lymphocytes was also decreased in TW samples from diseased camels. 


\section{Cytological analysis of tracheal wash and bronchoalveolar lavage fluid in} 2 health and respiratory disease in dromedary camels

3 Turke Shawaf $^{1^{*}}$, Abdullah I. A. Al-Mubarak ${ }^{2}$, Naser Abdallah Al Humam², Faisal Almathen ${ }^{3.4}$, 4 Jamal Hussen ${ }^{2}$

5 'Department of Clinical Sciences, College of Veterinary Medicine, King Faisal University, Al6 Ahsa, Saudi Arabia

$7{ }^{2}$ Department of Microbiology, College of Veterinary Medicine, King Faisal University, Al-Ahsa, 8 Saudi Arabia

$9{ }^{3}$ Department of Public Health, College of Veterinary Medicine, King Faisal University, Al-Ahsa, 10 Saudi Arabia

$11{ }^{4}$ The Camel Research Center, King Faisal University, Al-Ahsa, Saudi Arabia

14 Corresponding author:

15 Turke Shawaf

16 Department of Clinical Sciences, College of Veterinary Medicine, King Faisal University, Al-

17 Ahsa, 31982, Saudi Arabia; Phone: +966135896626; Fax: +966135896345; E-mail:

18 tshawaf@kfu.edu.sa 


\section{Abstract}

21 Background. Tracheal wash (TW) and bronchoalveolar lavage (BAL) have proven to be useful tools

22 for the identification of disease-associated changes in the respiratory tract in human and different

23 animal species. In the dromedary camel, little is known about cytological analysis of TW and BAL in

24 health and disease. The aim of the present study was to evaluate the cytological composition of TW

25 and BAL in health and respiratory disease in dromedary camels.

Methods. TW and BAL samples were collected from dromedary camels and cytological analysis was

27 performed by microscopic examination of prepared smears. Camels with clinical respiratory disease

$28(\mathrm{n}=18)$ were compared with apparently healthy (control) camels $(\mathrm{n}=9)$.

29 Results. In the apparently healthy camels, differential cytological analysis of TW samples identified macrophages and neutrophils as the main cell populations with lesser proportions of lymphocytes and epithelial cells and very rare abundance of eosinophils and mast cells. In the TW of camels with respiratory disease, neutrophils were the most abundant cells followed by macrophages and lymphocytes. In the BAL of healthy camels, macrophages represented the main cell type followed by

34 lymphocytes and neutrophils. In respiratory-diseased camels, BAL samples contained higher percentages of neutrophils with reduced percentages of macrophages and lymphocytes in comparison to camels from the control group. Collectively, the results of the current study revealed higher abundance of neutrophils in the TW and BAL from dromedary camels than many other veterinary species. The cytological patterns of TW and BAL from camels with respiratory diseases were characterized by increased proportion of neutrophils and decreased proportion of macrophages in comparison to healthy camels. The proportion of lymphocytes was also decreased in TW samples

41 from diseased camels. 
43 Keywords: bronchoalveolar lavage; camel; cytology; respiratory; tracheal wash

44 


\section{Introduction}

46 The dromedary camel (Camelus dromedarius) belongs to the most important domestic animal

47 species adapted to dry and hot regions in Asia and Africa (Kebedi 2010). The camel world

48 population is around 30 million heads (Faye 2015). Respiratory diseases are among the main

49 factors responsible for high mortality rates in dromedary camels (Al-Ruwaili et al. 2012; Bakhesh

50 Alhendi 2000; Gebru et al. 2018; Li et al. 2017; Scaglione et al. 2017). Among respiratory

51 infectious diseases, viral and bacterial infections are usually correlated with most losses (Schwartz

52 HJ 1992). The main viral respiratory pathogens in camels include adenovirus, parainfluenza 3

53 virus (Kebedi 2010), morbilivirus (Al-Rawashdeh et al. 2000), and MERS Coronavirus, which is

54 among the emerging public health hazards (Memish et al. 2013). Bacterial infections of the

55 respiratory tract of camels have been shown to be mainly caused by Manhaemiya hemolytica,

56 Corynebacterium spp., Pasteurella spp., and Arcanobacterium pyogenes (Wareth et al. 2014;

57 Wernery 2002).

58 The early diagnosis of respiratory disorders is a key factor for choosing specific treatment to

59 prevent disease progression and chronic lung disease (Intisar et al. 2009; Intisar et al. 2010a; Intisar

60 et al. 2010b; Kebedi 2010). Tracheal wash (TW) and bronchoalveolar lavage (BAL) are valuable

61 tools widely used for the investigation of the respiratory tract in human (Rose \& Knox 2007b),

62 horses (Orard et al. 2016), cattle (Pringle et al 1988; Abutarbush et al. 2019; Kokotovic et al.

63 2007), sheep (Katsoulos et al. 2009), pigs (Weissenbacher-Lang et al. 2016), alpaca (Pacheco

64 2012), dogs (Creevy 2009; Zhu et al. 2015), and cats (Lin et al. 2015). TW and BAL samples are

65 valuable mirrors of different areas of the airways and can be used in combination with other

66 methods for the diagnosis of lower respiratory tract inflammation (Malikides et al. 2003). Being 
67 able to explore large areas of the lower respiratory tract (Hoffman 2008), BAL is widely used as a

68 source for specimens for cytological, microbiological and immunological investigation of the

69 respiratory tract (Couetil et al. 2007; Hoffman 2008; Hoffman et al. 1998; Rose \& Knox 2007a).

70 BAL and TW samples are also useful in giving an insight on the severity and stage of inflammatory

71 reactions in the lung and in the detection of subclinical pulmonary diseases (Caldow 2001).

72 Species-specific differences have been reported regarding the selection of the appropriate

73 technique for sampling the respiratory secretions. In horses, TW is preferred for diagnosis of

74 respiratory infections, whereas BAL is the best choice for the diagnosis of non-infectious

75 pulmonary diseases (Davis \& Sheats 2019). However, similar diagnostic values have been reported

76 for BAL and TW for the diagnosis of common bacterial and viral respiratory pathogens in cattle

77 (Doyle et al. 2017). Although respiratory cytology may rapidly provide a presumptive diagnosis

78 of infection, identification of the etiologic agent requires bacterial or viral culture or PCR (Jocelyn

79 et al. 2018).

80 Although some studies reported the cytological composition of TW samples in camels (Habasha

81 \& Hussain 2014; Habasha \& Hussain 2016), there have been no studies conducted on the

82 comparative analysis of TW and BAL cytology in dromedary camels. The aim of the current study,

83 therefore, was to comparatively analyze the TW and BAL cytology in healthy and respiratory-

84 diseased dromedary camels.

\section{Materials \& Methods}


86

87 All experimental procedures used in this study were approved by the Ethics Committee at King

88 Faisal University, Saudi Arabia (Permission number KFU-REC / 2019 - 10 - 01). All applicable

\section{Ethical approval} international, national, and institutional (King Faisal University) guidelines for the care and use of animals were followed.

\section{Animals and experimental design}

Twenty-seven camels (Camelus dromedaries) of different ages, sex, and breeds were involved in this study. The control group included nine healthy camels (five males and four females with a median age \pm SEM of $10.3 \pm 5.5$ years and a median weight \pm SEM of $390 \pm 125 \mathrm{~kg}$ ) selected from animals maintained at the Camel Research Center at the King Faisal University, Al-Ahsa, Saudi Arabia. The diseased animal group included eighteen camels (seven males and eleven females with a median age \pm SEM of $12 \pm 6$ years and a median weight \pm SEM of $405 \pm 185 \mathrm{~kg}$ ) randomly selected from respiratory-diseased camels brought to the Veterinary Teaching Hospital, College of Veterinary Medicine, King Faisal University. Control camels were selected based on clinical scoring, physical, and laboratory evaluation (no fever or signs of abnormal respiratory signs such as cough, nasal discharge, dyspnea or abnormal lung sounds as well as normal white blood cell counts and biochemistry panel).

\section{Clinical examination}

For all animals, detailed history and clinical examination signs (dyspnea, cough and nasal discharge, lung sounds, and rate of breathing) were recorded. For the clinical evaluation of control and respiratory diseased camels, a scoring system designed for healthy and respiratory diseased 
107 horses (Ohnesorge 1998) was adapted with a modification by considering the animal rectal

108 temperature in the scoring procedure (Love et al. 2014) (Table 1). Clinical score points were

109 recorded by two persons. However, the data could not be taken blindly due to the difficulty of

110 taking the case history twice in the hospital. Camels with a clinical score less than three points

111 were considered healthy while camels with three or higher score points were considered diseased.

\section{Bronchoscopy and collection of TW and BAL samples}

113 For bronchoscopy, camels were positioned in sternal recumbency position. Due to the narrow nasal

114 passage in camels, especially in the Omani breed, and the lack of camel-specific endoscope and

115 BAL catheters, endoscope and BAL catheters were inserted via the oral cavity. After the

116 intravenous injection of xylazine $2 \%(0.1 \mathrm{mg} / \mathrm{kg}$ bodyweight; Rompun, Bayer Health Care $)$

117 (Shawaf 2017), a special mouth gag especially designed for camels in the Veterinary Teaching

118 Hospital (Fig. 1) was placed to keep the mouth open protecting and allowing easy passage of the

119 endoscope. The sedation was maintained throughout the whole endoscopic TW and BAL

120 collection procedures by intravenous injecting xylazine $(0.05 \mathrm{mg} / \mathrm{kg})$. A flexible $3.2 \mathrm{~m}$ long, 12

$121 \mathrm{~mm}$ tip diameter bronchoscope (EVIS Olympus, OLYMPUS AUSTRIA GmbH., Vienna),

122 supported with an insufflation system, light source, and irrigation system was introduced into the

123 oral cavity. When reached the pharynx, the endoscope was inserted via the rima glottidis into the

124 trachea. A tiny sterile plastic catheter (EQUIVET; 2,3 $\mathrm{mm}$ x $350 \mathrm{~cm}$ ) was passed into the

125 endoscope's working channel and TW was done by the injection of 10-15 mL sterile normal saline

126 into the last part of the trachea followed by immediate aspirating to recover TW fluid. The retrieved

127 fluid was collected into plain tubes for cytological analysis (within 15 min of collection). BAL

128 was performed immediately after the endoscopy and TW procedure. To decrease coughing during

129 BAL, 20-40 mL of 1\% lidocaine was infused as local anesthesia into the lower airway. A catheter 
130 (EQUIVET B.A.L. catheter $240 \mathrm{~cm}$, KRUUSE, Denmark) was passed through the speculum of

131 mouth gag into the oral cavity until the pharynx and then advanced into the larynx, trachea, and

132 bronchi until reaching a slight resistance (Fig. 2). As we faced difficulties to introduce the BAL

133 catheter blind into the larynx, we used an endoscope for guiding the BAL catheter into the larynx.

134 As soon as the tube was wedged into the bronchus, the cuff was then gently inflated using 10-20

$135 \mathrm{ml}$ of air to prevent the backflow of infused fluid. Five syringes (each of $50 \mathrm{ml}$ ) of sterile isotonic

136 saline were placed in a water-bath to warm up to approximately $37^{\circ} \mathrm{C}$ and were then instilled via

137 BAL catheter. BAL was aspirated immediately after injection and the samples were immediately

138 positioned on ice and submitted to the lab within $30 \mathrm{~min}$ of collection. Samples were considered

139 acceptable when they contained a foamy surfactant layer. BAL samples were used for cytological

140 analysis within one hour after sample collection.

141 Cytological analysis of TW and BAL samples

142 The total cell count of BAL samples was estimated by taking a small volume from the well mixed

143 original fluid in a Bürker's counting hemocytomer (Laporoptic, Germany) after filtering the

144 sample through a gauze. For differential cell counting, the TW and BAL samples were centrifuged

145 at $1500 \mathrm{rpm}$ for 15 minutes and the supernatant was discarded. Microscopic smears were prepared

146 from the cell pellet and air dried smears were stained using the Diff Quick staining kit (Hemal

147 Stain Co. Inc., Danbury, CT). The cytological analysis was performed by a specialist in clinical

148 pathology, who was blinded to the camel health status. Using a magnification of $1000 \times$ and a

149 standardized counting protocol (De Brauwer et al. 2000; De Brauwer et al. 2002), the percentages

150 of macrophages, lymphocytes, neutrophil, mast cells, eosinophils, and epithelial cells were

151 calculated after counting a minimum of 400 cells.

\section{Statistical analysis}


153 Using the statistical software Graph Pad Prism 5, differences between the means were analyzed

154 using the one-way analysis of variance (ANOVA) in combination with the Bonferroni post test for

155 multi-comparison analysis. Normal distribution was evaluated by D'Agostino \& Pearson omnibus

156 normality test. The differences between the groups were considered significant if the $P$-value was

157 less than 0.05.

\section{Results}

159 For the cytological analysis of tracheal wash (TW) and bronchoalveolar lavage (BAL) in healthy

160 and respiratory diseased dromedary camels, a scoring system was used to group camels into a

161 healthy control group $(n=9)$ and a respiratory diseased group $(n=18)$. All examination parameters

162 and scoring points were within the normal ranges in the animals from the control group with no

163 abnormal respiratory sounds or any signs of respiratory disorders or infections (clinical score $<3$

164 points with a mean \pm SEM of $0.88 \pm 0.75)$. The diseased group showed varying signs of respiratory

165 signs like cough, nasal discharges, and abnormal respiratory sounds (clinical score $\geq 3$ points with

166 a mean \pm SEM of $7.9 \pm 3.4)$. Endoscopic visualization of the mucosa lining the trachea and bronchi

167 also revealed no abnormal mucus accumulation in healthy animals, while there was varying

168 degrees of mucus accumulation and narrowing in the airways of diseased camels. From the total

169 instilled $250 \mathrm{~mL}$ fluids, the retrieved fluids were $155 \pm 35.2 \mathrm{~mL}$, representing $62 \pm 14.8 \%$ of the

170 total instilled fluids. No differences in the volume of the retrieved fluid were observed between

171 healthy and diseased camels.

172 Due to specific anatomical and physiological characteristics of the pharynx cavity and the long

173 soft palate (Dulla) in the camel, we needed to use visual endoscopy in eight cases to introduce the

174 BAL catheter into the larynx. 


\section{Identification of different cell types in camel TW and BAL samples}

176 In both TW and BAL samples, camel alveolar macrophages were slightly variable in size with

177 abundant vacuolated cytoplasm and irregular cell margins (Fig.3A and 3E). Macrophages

178 cytoplasmic vacuoles occasionally contained cellular debris (Fig.3E). BAL neutrophils were

179 normally segmented and non-degenerative, which is similar to blood neutrophils, whereas TW

180 neutrophils were segmented and degenerated (Fig.3A). Lymphocytes were characterized by small

181 round central to eccentric nuclei with dense clumped chromatin and scant amounts of blue

182 cytoplasm with smooth margins (Fig. 3E). Eosinophils were identified based on their uniformly

183 sized small red orange cytoplasmic granules (Fig. 3C). Epithelial cells were found as ciliated

184 columnar cells with basally located nucleus. Some epithelial cells showed loss of cilia, which were

185 seen in the background of the slides (Fig.3A and F). In general, TW cells were frequently

186 degenerated and more difficult to be differentiated in comparison to BAL cells. In some TW slides,

187 contamination with bacteria, saliva, food material, red blood, or oral squamous epithelial cells was 188 observed (Fig.3D).

189 Cellular composition of TW and BAL samples from healthy and diseased camels

190 BAL samples from diseased camels contained significantly more cells $(824 \pm 401.1$ cells $/ \mu \mathrm{L})$ than

191 BAL samples from the control group $(200.4 \pm 39.2$ cells $/ \mu \mathrm{L})$ (Table.2). Due to high mucus

192 accumulation in the samples, we found difficulties in the estimation of total cell counts in the TW

193 samples.

194 The differential cell counts of the TW fluids in healthy camels consisted primarily of macrophages

$195(51.6 \pm 10.2 \%)$ and neutrophils $(27.3 \pm 7.2 \%)$ with lesser frequency of lymphocytes $(8.2 \pm 1.3 \%)$,

196 epithelial cells $(8.8 \pm 5.1 \%)$, eosinophils $(1.7 \pm 0.4 \%)$, and mast cells $(1 \pm 0.4 \%)$. In the TW 
197 samples from diseased camels, neutrophils were the most abundant cells (73.3 $\pm 7.4 \%)$ followed

198 by macrophages $(22.4 \pm 7.6 \%)$ with lower percentages of lymphocytes $(3.2 \pm 1.2 \%)$, mast cells

$199(1.3 \pm 0.1 \%)$, epithelial cells $(1.2 \pm 0.3 \%)$, and eosinophils $(0.5 \pm 0.4 \%)$ (Fig.4A-F).

200 The differential cell counts of the BAL in healthy camels revealed the dominance of macrophages $201(60.0 \pm 3.1 \%)$ and lymphocytes $(23.7 \pm 1.9 \%)$ with low proportions of neutrophils $(7.9 \pm 1.8 \%)$ 202 and epithelial cells $(5.4 \pm 1.2 \%)$ and rarely seen mast cells $(0.6 \pm 0.2 \%)$ and eosinophils

$203(1.6 \pm 0.5 \%)$. BAL samples from diseased camels showed reduced percentage of macrophages $204(52.6 \pm 4.2 \%)$ and lymphocytes $(15.8 \pm 6.1 \%)$ but increased percentage of neutrophils $205(24.7 \pm 4.7 \%)$ when compared to healthy animals. However, the percentage of epithelial cells $206(5.2 \pm 1.2 \%)$ was similar in healthy and diseased camels (Fig.4A-F). Based on their rectal 207 temperature, the studied animals were classified into animals with low temperature $(<39)$ and 208 animals with high $(>39.1)$ temperature. BAL samples from the animal group with high rectal 209 temperature contained significantly more cells $(1653 \pm 235.6$ cells $/ \mu \mathrm{L})$ than BAL samples from 210 the normal group $(587 \pm 115.7$ cells $/ \mu \mathrm{L})($ Table.3). For both TW and BAL samples, the percentage 211 of neutrophils was higher in the camels with high rectal temperature . In addition, there was a 212 decrease in the percentage of macrophage in TW and BAL samples in animals with high rectal 213 temperature compared to animals with normal rectal temperature (Table.3).

\section{Discussion}

215 In the current study, the cytological composition of tracheal wash (TW) and bronchoalveolar lavage

216 (BAL) samples were comparatively analyzed in apparently healthy camels and camels with clinical 217 respiratory diseases. The cytological patterns of TW and BAL from camels with respiratory 218 diseases were characterized by increased proportion of neutrophils and decreased proportion of 
219 macrophages in comparison to healthy camels. The proportion of lymphocytes was also decreased

220 in TW samples from diseased camels, when compared to healthy camels.

221 The detecting of oral epithelial cells with bacterial contamination in TW slides may affect the

222 cytological analysis and argues against using TW for bacterial examination (Smith 2019). In the

223 horse, other sampling techniques have been suggested for obtaining uncontaminated lower airway

224 secretions for bacterial culture. This includes the transtracheal aspiration after the insertion of a

225 sterile flushing tube through a tracheal cannula between tracheal rings below the larynx. In

226 addition, the protected aspiration catheter technique using a guarded sterile tube, due to its reduced

227 complication risk, has been suggested as an alternative to the transtracheal aspiration for the

228 isolation of equine pulmonary bacteria (Darien et al. 1990). However, comparative studies are

229 required to determine the most optimal sampling technique for the collection of camel lower

230 airway fluids for bacterial culture.

231 TW contamination with saliva might have resulted from oral saliva coming down from the oral

232 cavity into the airways during endoscopy. As shown in Fig. 3D, the presence of some red blood

233 cells in TW could be due to minimal bleeding during sample collection (Hughes et al. 2003). Our

234 results are also in agreement with Walker et al. (2006), who observed that BAL cells are better

235 preserved and usually easier to be identified than TW cells.

236 Due to limited information about cytological values in camels, the results from the current work

237 were compared with data reported for other species. In our study, the total cell count of BAL in

238 healthy camels was similar to results reported for the bovine BAL cytology (Abutarbush et al.

239 2019). Similar to other species, including cattle, horses, and donkeys (Abutarbush et al. 2019;

240 Hoffman 2008; Rossi et al. 2018; Shawaf 2019), respiratory diseases in camels were associated 
241 with increased total cell count in the BAL fluid. For cattle with respiratory diseases, however,

242 greater increase in the total BAL cell count was reported (Thirunavukkarasu et al. 2005).

243 Similar to their distribution in healthy horses (Malikides et al. 2003), neutrophils were found in

244 higher proportions in TW than in BAL fluids from healthy camels. The increased fraction of

245 neutrophils in TW and BAL fluids from camels with respiratory diseases is also in line with

246 findings in respiratory diseased horses (Rossi et al. 2018), donkeys (Shawaf 2019), cattle

247 (Kokotovic et al. 2007), and alpaca (Pacheco 2012).

248 In the present study, the decreased fraction of macrophages in TW and BAL from diseased camels

249 is in line with reports from other species, including human (Rose \& Knox 2007b), horses (Rossi

250 et al. 2018), cattle (Kokotovic et al. 2007), and alpaca (Pacheco 2012). The lower frequency of

251 macrophages in diseased animals may be a result of the increased accumulation of neutrophils in

252 the respiratory secretions. Further studies are needed to see, whether this change in macrophages

253 count is also associated with modifications in their functional type.

254 Although the proportion of lymphocytes in the BAL fluids from healthy camels is comparable

255 with their percentage in equine BAL fluids, healthy camel TW contained only a minor population

256 of lymphocytes, which is in contrast to the equine system, where TW lymphocytes are also the

257 second dominant population after macrophages (Richard et al. 2010). In contrast to finding in the

258 horse, where changes in the percentage of BAL and TW lymphocytes were of lower relevance for

259 the diagnosis of equine respiratory disorders (Hoffman et al. 1998; Rossi et al. 2018; Shawaf 2019),

260 we found significantly less lymphocytes in TW of respiratory diseased camels. Whether these

261 differences in the cellular composition of respiratory secretions rely on species-specific defense

262 mechanisms in the respiratory tract, further comparative studies are required. Furthermore, as 
263 lymphocytes are a heterogeneous cell population, it still to be investigated, whether selective

264 lymphocyte subsets like helper or cytotoxic T cells, B cells, or NK cells, were especially affected

265 by this decrease.

266 The low frequency of eosinophils (Abutarbush et al. 2019; Hughes et al. 2003) and mast cells

267 (Hughes et al. 2003; Leclere et al. 2006; Malikides et al. 2003) in BAL and TW from healthy

268 camels of the present study is in agreement with results from other species. Although the diagnostic

269 value of mast cells in BAL and TW are not fully studied (Rossi et al. 2018), we found significantly

270 more mast cells in the BAL from diseased camel, which is similar to results reported for diseased

271 horses (Leclere et al. 2006).

272 As normal cells lining the trachea, epithelial cells are present in high numbers in a normal tracheal

273 wash (Zhu et al. 2015) but only in low numbers in BAL samples (Hoffman 2008). The higher

274 frequency of epithelial cells in TW from healthy than respiratory diseased camels is in contrast to

275 reports from previous studies conducted in horses (Wysocka \& Klucinski 2015). Interestingly, we

276 found in some TW samples from diseased camels separated epithelial cell cilia, which could have

277 originated from the inflamed airways (McCauley et al. 1998; Simet et al. 2010; Sisson et al. 1994).

278 In human, ciliocytophthoria of nasal epithelial cells has been reported after viral infections

279 (Gelardi \& Ciprandi 2019). Investigating the clinical significance of the observed ciliated epithelial

280 cells and its association with viral pathogens, however, requires further studies.

281 Finally, one of the limitations of the present study is the cell identification method. Although it is

282 widely used for cytological analysis in several species (Jackson et al. 2013), staining with

283 Diffquick may fail to reliably identify all cell types (Leclere et al. 2006). Specifically, the estimated

284 frequency of mast cells in the BAL samples may have been affected by Diffquick staining. 
285 However, mast cells represent only a minor fraction within BAL cells, which argues against a

286 significant impact of the staining method on the results of cytological analysis in the present study.

287 The identification of mast cells in other species relies on histochemical stains for their heparin,

288 glycosaminoglycans, or esterase. In addition, different antibodies have been used to identify mast

289 cells in human (Ribatti 2018). Therefore, the identification of cross-reactive antibodies to camel

290 mast cell markers would enable their confirmed immunophenotypic identification in camels. In

291 addition, the identification of functional cell subtypes, including pro-inflammatory (M1) and anti-

292 inflammatory (M2) macrophages, would help in better understanding and interpretation of

293 cytological findings. For this, a combination of cell labeling with monoclonal antibodies to

294 selected cell surface markers with flow cytometric analysis may be a good alternative to Diffquick

295 staining.

296 Conclusion

297 The present study provides the first report on the comparative analysis of TW and BAL cytology

298 in dromedary camels. Dromedary camels show higher abundance of neutrophils in their TW and

299 BAL than many other veterinary species. The cytological patterns of TW and BAL from camels

300 with respiratory diseases are characterized by increased proportion of neutrophils and decreased

301 proportion of macrophages in comparison to healthy camels. The proportion of lymphocytes was

302 decreased only in TW samples from diseased camels. Collectively, BAL and TW represent

303 valuable techniques for detailed investigation of disease-associated cytological changes in the

304 respiratory tract of camels.

\section{Acknowledgements}


306 The Authors acknowledge the Deanship of Scientific Research at King Faisal University, Al-Ahsa,

307 Saudi Arabia, for the financial support under Research Group Support Track (Grant No. 1811001).

308 References

309 Abutarbush SM, Al-Rukibat RK, Quran W, and Hananeh W. 2019. Laboratory findings of tracheal

310 wash and bronchoalveolar lavage in normal adult dairy cattle. Journal of Applied Animal

$311 \quad$ Research 47:46-53.

312 Al-Rawashdeh OF, Al-Ani FK, Sharrif LA, Al-Qudah KM, Al-Hami Y, and Frank N. 2000. A

313 survey of camel (Camelus dromedarius) diseases in Jordan. J Zoo Wildl Med 31:335-338.

314 10.1638/1042-7260(2000)031[0335:ASOCCD]2.0.CO;2

315 Al-Ruwaili MA, Khalil OM, and Selim SA. 2012. Viral and bacterial infections associated with 316 camel (Camelus dromedarius) calf diarrhea in North Province, Saudi Arabia. Saudi J Biol Sci 19:35-41. 10.1016/j.sjbs.2011.10.001

Bakhesh Alhendi AA. 2000. Common diseases of camels (camelus dromedarius) in Eastern province of Saudi Arabia. Pakistan Vet J, 2:97-99.

Caldow G. 2001. Bronchoalveolar lavage in the investigation of bovine respiratory disease. In Practice 23:41-43.

Couetil LL, Hoffman AM, Hodgson J, Buechner-Maxwell V, Viel L, Wood JL, and Lavoie JP. 2007. Inflammatory airway disease of horses. J Vet Intern Med 21:356-361.

324 Creevy KE. 2009. Airway evaluation and flexible endoscopic procedures in dogs and cats: laryngoscopy, transtracheal wash, tracheobronchoscopy, and bronchoalveolar lavage. Vet Clin North Am Small Anim Pract 39:869-880. 10.1016/j.cvsm.2009.05.001 
327 Darien BJ, Brown CM, Walker RD, Williams MA, and Derksen FJ. 1990. A tracheoscopic

328 technique for obtaining uncontaminated lower airway secretions for bacterial culture in the 329 horse. Equine Vet J 22:170-173. 10.1111/j.2042-3306.1990.tb04239.x

330 Davis KU, and Sheats MK. 2019. Bronchoalveolar Lavage Cytology Characteristics and Seasonal 331 Changes in a Herd of Pastured Teaching Horses. Front Vet Sci 6:74.

333 De Brauwer EI, Drent M, Mulder PG, Bruggeman CA, Wagenaar SS, and Jacobs JA. 2000. Differential cell analysis of cytocentrifuged bronchoalveolar fluid samples affected by the area counted. Anal Quant Cytol Histol 22:143-149.

De Brauwer EI, Jacobs JA, Nieman F, Bruggeman CA, and Drent M. 2002. Bronchoalveolar lavage fluid differential cell count. How many cells should be counted? Anal Quant Cytol Histol 24:337-341.

Doyle D, Credille B, Lehenbauer TW, Berghaus R, Aly SS, Champagne J, Blanchard P, Crossley B, Berghaus L, Cochran S, and Woolums A. 2017. Agreement Among 4 Sampling

Faye B. 2015. Role, distribution and perspective of camel breeding in the third millennium Methods to Identify Respiratory Pathogens in Dairy Calves with Acute Bovine Respiratory economies. Emir J Food Agric 27:318-327.

Gebru M, Tefera G, Dawo F, and Tessema TS. 2018. Aerobic bacteriological studies on the respiratory tracts of apparently healthy and pneumonic camels (Camelus dromedaries) in selected districts of Afar Region, Ethiopia. Trop Anim Health Prod 50:603-611. $10.1007 / \mathrm{s} 11250-017-1476-4$ 
349 Gelardi M, and Ciprandi G. 2019. Ciliocytophthoria of nasal epithelial cells after viral infection: a 350 sign of suffering cell. Acta Biomed 90. 10.23750/abm.v90i2-S.8103

351 Habasha FG, and Hussain MH. 2014. Cytological analysis of transtracheal washes from healthy

352

353

354

355

356

357

358

359

360

361

362

363

364

365

366

367

368

369 camels in Al-diwaniya province. Al-Qadisiyah Journal of Veterinary Medicine Sciences $13: 124-127$.

Habasha FG, and Hussain MH. 2016. Clinical \& Diagnostic Study of E-coli from Camels with Pneumonia using VITEK 2 Compact, Histopathology \& Conventional PCR. First scientific conference. Vet. Med. Coll: Univ. of Baghdad.

Hoffman AM. 2008. Bronchoalveolar lavage: sampling technique and guidelines for cytologic preparation and interpretation. Vet Clin North Am Equine Pract 24:423-435, vii-viii. 10.1016/j.cveq.2008.04.003

Hoffman AM, Mazan MR, and Ellenberg S. 1998. Association between bronchoalveolar lavage cytologic features and airway reactivity in horses with a history of exercise intolerance. $\mathrm{Am}$ J Vet Res 59:176-181.

Hughes KJ, Malikides N, Hodgson DR, and Hodgson JL. 2003. Comparison of tracheal aspirates and bronchoalveolar lavage in racehorses. 1. Evaluation of cytological stains and the percentage of mast cells and eosinophils. Aust Vet J 81:681-684. 10.1111/j.17510813.2003.tb12538.x

Hussen J, Shawaf T, Jashan M, and Schuberth HJ. 2019. Whole blood stimulation with lipopolysaccharide modulates phenotype and function of dromedary camel neutrophils. Journal of Camel Practice And Research 26:105-110. 
370 Intisar KS, Ali YH, Khalafalla AI, Mahasin EA, and Amin AS. 2009. Natural exposure of

371 Dromedary camels in Sudan to infectious bovine rhinotracheitis virus (bovine herpes virus-

372 1). Acta Trop 111:243-246. 10.1016/j.actatropica.2009.05.001

373 Intisar KS, Ali YH, Khalafalla AI, Rahman ME, and Amin AS. 2010a. Respiratory infection of

374 camels associated with parainfluenza virus 3 in Sudan. J Virol Methods 163:82-86.

$375 \quad$ 10.1016/j.jviromet.2009.08.017

376 Intisar KS, Ali YH, Khalafalla AI, Rahman ME, and Amin AS. 2010b. Respiratory syncytial virus

377 infection of camels (Camelus dromedaries). Acta Trop 113:129-133.

$378 \quad 10.1016 /$ j.actatropica.2009.10.005

379 Jackson DE, Selting KA, Spoor MS, Henry CJ, and Wiedmeyer CE. 2013. Evaluation of fixation

380 time using Diff-Quik for staining of canine mast cell tumor aspirates. Vet Clin Pathol

381 42:99-102. 10.1111/vcp.12012

382 Jocelyn NA, Wylie CE, Lean M, Barrelet A, and Foote AK. 2018. Association of neutrophil 383 morphology with bacterial isolates in equine tracheal wash samples. Equine Vet J 50:752758. $10.1111 /$ evj.12837

385

Katsoulos PD, Christodoulopoulos G, Kontopidis G, Minas A, Tzivara A, and Kritas SK. 2009. Leukocyte counts in bronchoalveolar lavage fluid obtained from normal and Maedi-Visnainfected sheep. Vet Clin Pathol 38:397-402. 10.1111/j.1939-165X.2009.00129.x

Kebedi FG, E. 2010. Studies on major respiratory diseases of Camel (Camelus dromedarius) in Northeastern Ethiopia. African Journal of Microbiology Research 4:1560-1564.

Kokotovic B, Friis NF, and Ahrens P. 2007. Mycoplasma alkalescens demonstrated in bronchoalveolar lavage of cattle in Denmark. Acta Vet Scand 49:2. 10.1186/1751-014749-2 
393 Leclere M, Desnoyers M, Beauchamp G, and Lavoie JP. 2006. Comparison of four staining 394 methods for detection of mast cells in equine bronchoalveolar lavage fluid. $J$ Vet Intern 395 Med 20:377-381. 10.1892/0891-6640(2006)20[377:cofsmf]2.0.co;2

396

397

398

399

400

401

402

403

404

405

406

407

408

409

410

411

412

413

414

Li Y, Khalafalla AI, Paden CR, Yusof MF, Eltahir YM, Al Hammadi ZM, Tao Y, Queen K, Hosani FA, Gerber SI, Hall AJ, Al Muhairi S, and Tong S. 2017. Identification of diverse viruses in upper respiratory samples in dromedary camels from United Arab Emirates. PLoS One 12:e0184718. 10.1371/journal.pone.0184718

Lin $\mathrm{CH}$, Wu HD, Lee JJ, and Liu CH. 2015. Functional phenotype and its correlation with therapeutic response and inflammatory type of bronchoalveolar lavage fluid in feline lower airway disease. $J$ Vet Intern Med 29:88-96. 10.1111/jvim.12494

Love WJ, Lehenbauer TW, Kass PH, Van Eenennaam AL, and Aly SS. 2014. Development of a novel clinical scoring system for on-farm diagnosis of bovine respiratory disease in preweaned dairy calves. PeerJ 2:e238. 10.7717/peerj.238

Malikides N, Hughes KJ, Hodgson DR, and Hodgson JL. 2003. Comparison of tracheal aspirates and bronchoalveolar lavage in racehorses. 2. Evaluation of the diagnostic significance of neutrophil percentage. Aust Vet J 81:685-687. 10.1111/j.1751-0813.2003.tb12540.x

McCauley M, Atwell RB, Sutton RH, and Lumsden JS. 1998. Unguided bronchoalveolar lavage techniques and residual effects in dogs. Aust Vet J 76:161-165.

Memish ZA, Mishra N, Olival KJ, Fagbo SF, Kapoor V, Epstein JH, Alhakeem R, Durosinloun A, Al Asmari M, Islam A, Kapoor A, Briese T, Daszak P, Al Rabeeah AA, and Lipkin WI. 2013. Middle East respiratory syndrome coronavirus in bats, Saudi Arabia. Emerg Infect Dis 19:1819-1823. 10.3201/eid1911.131172 
415 Ohnesorge BT, C.; Deegen, E. 1998. Diagnostic value of capnography in horses with RAO. 5th $416 \quad$ World Equine Vet Assoc Congress. p 65-69.

417 Orard M, Depecker M, Hue E, Pitel PH, Courouce-Malblanc A, and Richard EA. 2016. Influence 418 of bronchoalveolar lavage volume on cytological profiles and subsequent diagnosis of inflammatory airway disease in horses. Vet J 207:193-195.

Pacheco APB, D.; Mazan, M.R.; Hoffman, A.M. 2012. Respiratory mechanics and results of cytologic examination of bronchoalveolar lavage fluid in healthy adult alpacas. Am $J$ Vet Res 93:146-152.

Pringle, JK., Viel, L., Shewen, PE., Willoughby, RA., Martin, SW., \& Valli, VE. 1988. Bronchoalveolar lavage of cranial and caudal lung regions in selected normal calves: cellular, microbiological, immunoglobulin, serological and histological variables. Can J Vet Res 52(2), 239-248.

Richard EA, Fortier GD, Lekeux PM, and Van Erck E. 2010. Laboratory findings in respiratory fluids of the poorly-performing horse. Vet $J$ 185:115-122. 10.1016/j.tvj1.2009.05.003

Rose AS, and Knox KS. 2007a. Bronchoalveolar lavage as a research tool. Seminars in Respiratory and Critical Care Medicine 28:561-573. 10.1055/s-2007-991528

Rose AS, and Knox KS. 2007b. Bronchoalveolar lavage as a research tool. Semin Respir Crit Care Med 28:561-573. 10.1055/s-2007-991528

Rossi H, Virtala AM, Raekallio M, Rahkonen E, Rajamaki MM, and Mykkanen A. 2018. Comparison of Tracheal Wash and Bronchoalveolar Lavage Cytology in 154 Horses With and Without Respiratory Signs in a Referral Hospital Over 2009-2015. Front Vet Sci 5:61. 10.3389/fvets.2018.00061 
437 Scaglione FE, Peano A, Piga S, Meda S, Bollo E, Cannizzo FT, Pasquetti M, and Jensen HE. 2017.

438 Scrotal granulomatous aspergillosis in a dromedary camel (Camelus dromedarius). BMC Vet Res 13:79. 10.1186/s12917-017-1001-z

440 Schwartz HJ DM. 1992. The one-humped camel (Camelus dromedarius) in eastern Africa. A 441 pictorial guide to diseases, health care and management.: Verlag Josef Margraf.

442

443

444

445

448

449

450

451

452

453

454

455

456

457 458

459

Shawaf T. 2019. Cytological Analysis of Tracheal Washing and Bronchoalveolar Lavage Fluid Obtained from Donkeys with Chronic Lung Disease. Alexandria Journal of Veterinary Sciences 60:15-21. DOI: 10.5455/ajvs.20051

Shawaf T, Ramadan, O.R., Elnahas, A., Eljalii, I., Al Salman, M.F. 2017. Oesophagoscopy and Endoscopic Aided Removal of Oesophageal Foreign Bodies in Camel Calves (Camelus dromedarius). Journal of Camel Practice And Research.

Simet SM, Sisson JH, Pavlik JA, Devasure JM, Boyer C, Liu X, Kawasaki S, Sharp JG, Rennard SI, and Wyatt TA. 2010. Long-term cigarette smoke exposure in a mouse model of ciliated epithelial cell function. Am J Respir Cell Mol Biol 43:635-640. 10.1165/rcmb.2009$02970 \mathrm{C}$

Sisson JH, Papi A, Beckmann JD, Leise KL, Wisecarver J, Brodersen BW, Kelling CL, Spurzem JR, and Rennard SI. 1994. Smoke and viral infection cause cilia loss detectable by bronchoalveolar lavage cytology and dynein ELISA. Am J Respir Crit Care Med 149:205213. 10.1164/ajrccm.149.1.8111584

Smith S. 2019. Interpretation of tracheal wash samples in horses. In Practice 4:220-226.

Thirunavukkarasu P, Senthilkumar G, Balachandran C, and Vasu K. 2005. Bronchoalveolar lavage fluid (BALF) cytological findings in bovine respiratory disorders (BRD). Indian journal of animal research 39:137-139. 
460 Walker HJ, Evans DL, Slocombe RF, Hodgson JL, and Hodgson DR. 2006. Effect of 461 corticosteroid and bronchodilator therapy on bronchoalveolar lavage cytology following 462 intrapulmonary blood inoculation. Equine Vet J Suppl:516-522. 10.1111/j.2042463 3306.2006.tb05597.x

464 Wareth G, Murugaiyan J, Khater DF, and Moustafa SA. 2014. Subclinical pulmonary pathogenic 465 466 infection in camels slaughtered in Cairo, Egypt. $J$ Infect Dev Ctries 8:909-913. $10.3855 /$ jidc. 4810

467 Weissenbacher-Lang C, Nedorost N, Knecht C, Hennig-Pauka I, and Weissenbock H. 2016. 468 Establishment of a quantitative real-time PCR for the detection of Pneumocystis carinii $\mathrm{f}$. 469 sp. suis in bronchoalveolar lavage samples from pigs. $J$ Vet Diagn Invest 28:257-262.

471 Wernery UK, O.R. 2002. Infectious Diseases of Camelids. Berlin, Germany: Blackwell 472 Wissenschafts Verlag.

473 Wysocka B, and Klucinski W. 2015. Cytological evaluation of tracheal aspirate and bronchoalveolar lavage fluid in comparison to endoscopic assessment of lower airways in horses with recurrent airways obstruction or inflammatory airway disease. Pol J Vet Sci 18:587597. $10.1515 /$ pjvs-2015-0076

477 Zhu BY, Johnson LR, and Vernau W. 2015. Tracheobronchial brush cytology and bronchoalveolar 478 lavage in dogs and cats with chronic cough: 45 cases (2012-2014). J Vet Intern Med 479 29:526-532. 10.1111/jvim.12566 


\section{Figure 1}

Placement the endoscope to preform the endoscopic examination and TW sample collection from dromedary camel

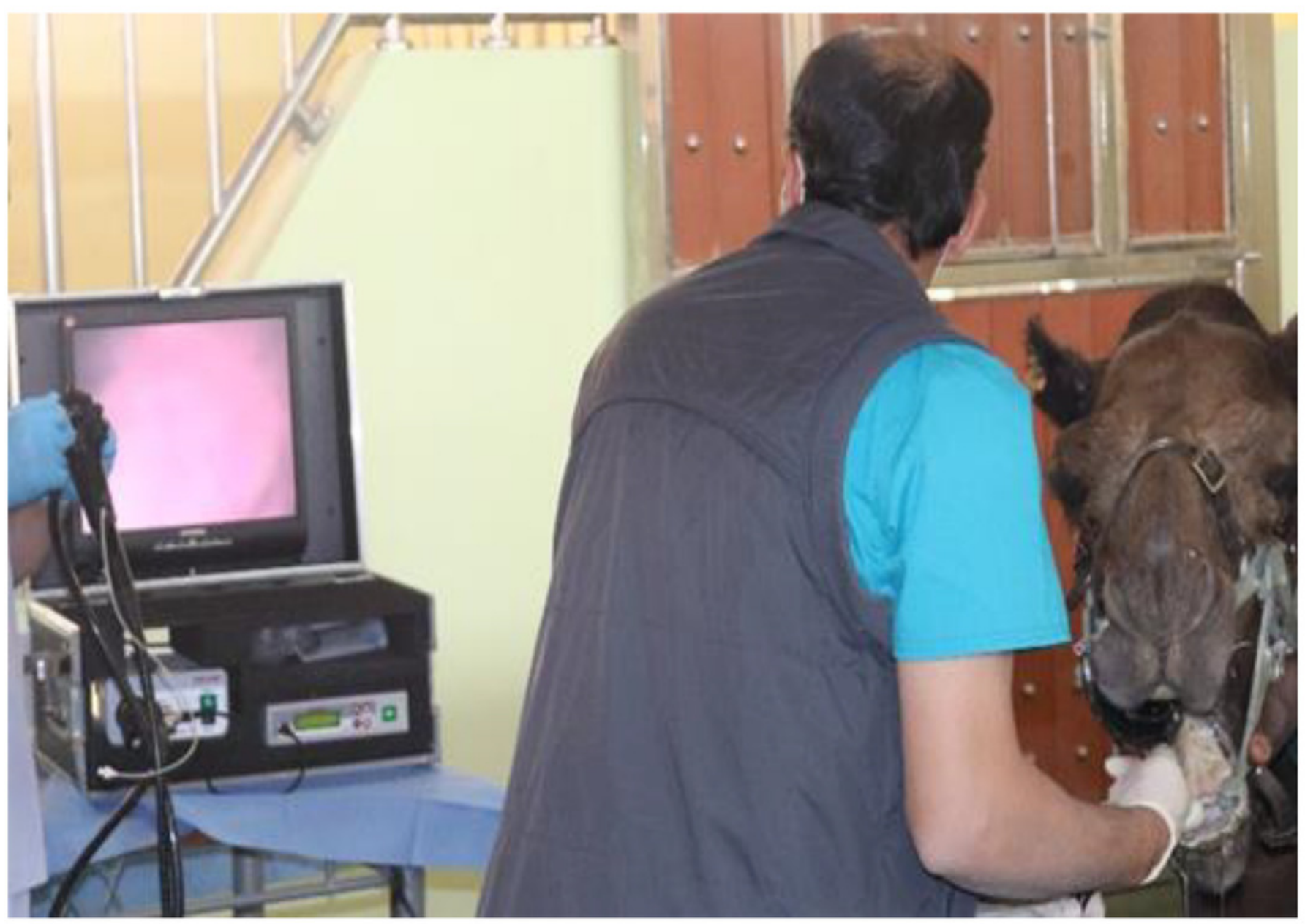




\section{Figure 2}

Bronchoalveolar lavage collection using BAL catheter from dromedary camel

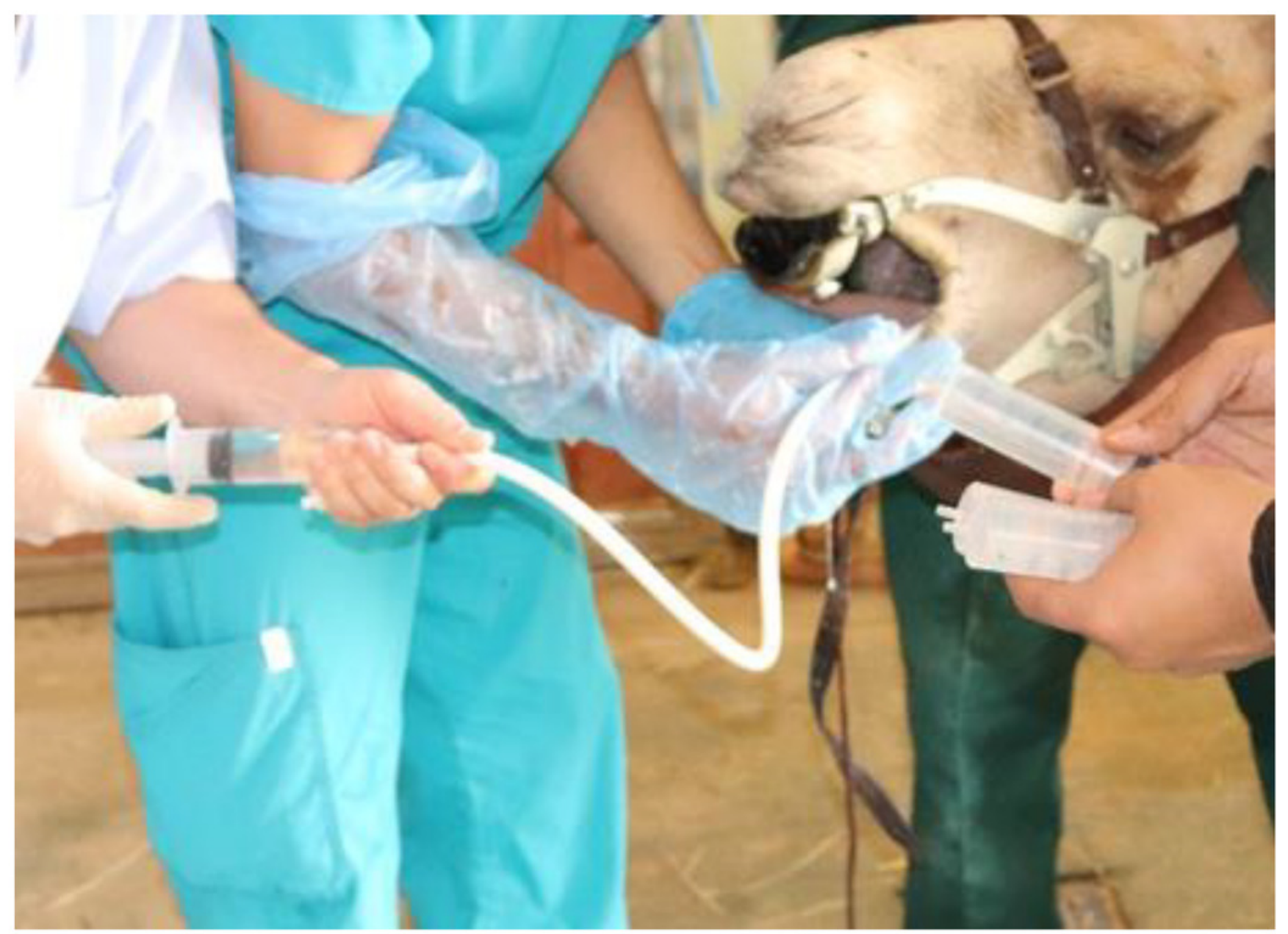




\section{Figure 3}

The identification of different cell types in TW and BAL samples.

Cytological slides were prepared from TW and BAL samples, stained with the Diff Quick stain, and examined microscopically: (A) A TW slide showing different cell types, including neutrophils (N) and epithelia cell (Ep) with a magnification of 1000x; (B) A TW slide from affected camel showing increased quantity of degenerated neutrophils with a magnification of 200x; (C) A TW slide from a camel with respiratory disease showing degenerated neutrophils. This field also shows an eosinophil cell with granules within the cytoplasm with a magnification of 1000x; (D) A TW slide from a camel with respiratory disease showing oral epithelial cells (O Ep), bacteria (B), red blood cells (RBC), and separated cilia (C). Stain Diff Quick stain; magnification, 1000x; (E) A BAL slide prepared from a healthy camel showing macrophages (M) and Lymphocytes (L); (F) A BAL slide from a camel with respiratory disease showing increased numbers of neutrophils. In addition, macrophages (M), alveolar macrophage (AM), lymphocytes (L), and Epithelia cell (Ep) can be identified in the field; magnification, 1000x. 


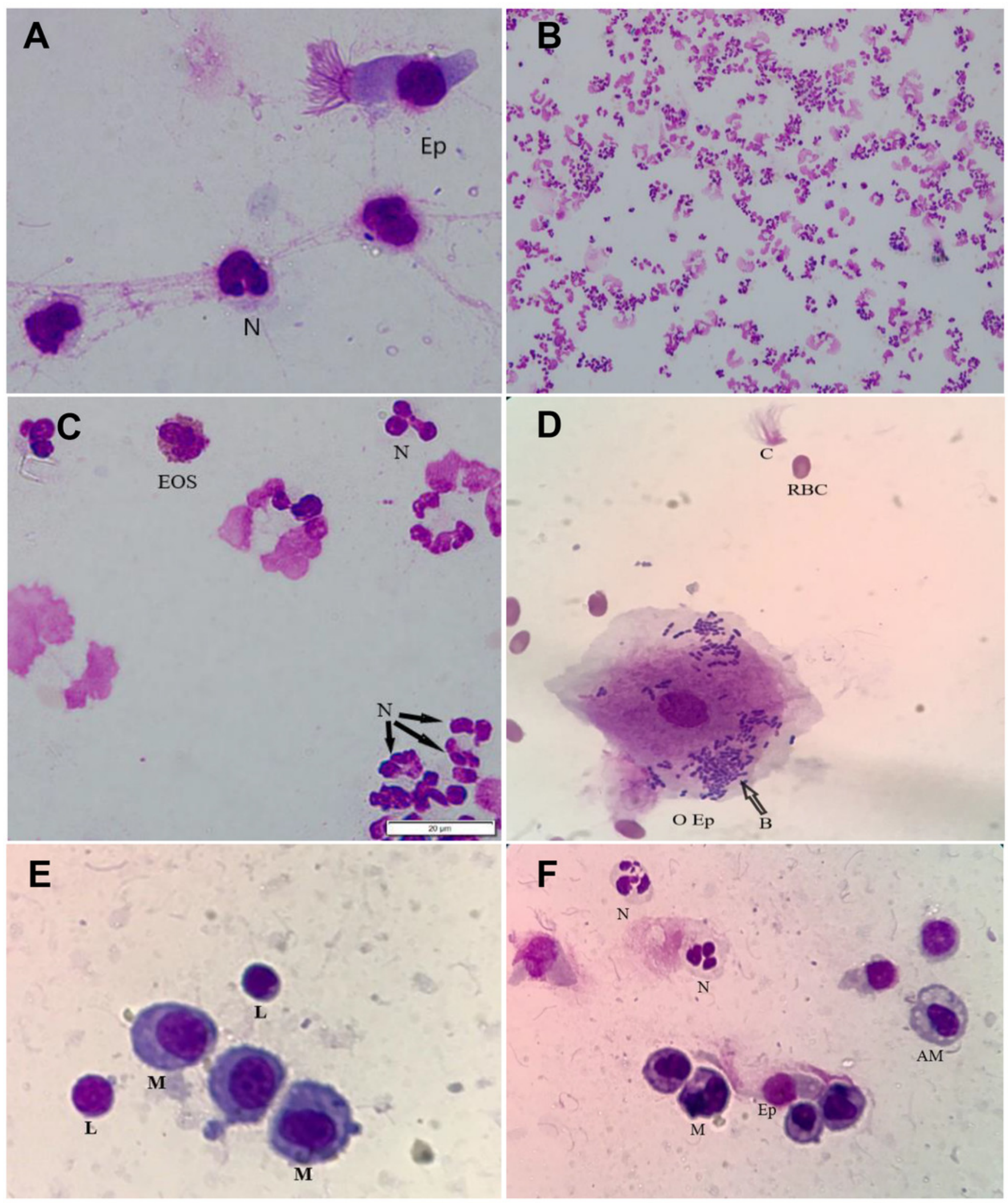




\section{Figure 4}

The differential composition of TW and BAL samples

The differential composition of TW and BAL samples. Cytological slides were prepared from TW and BAL samples, stained with the Diff Quick stain, and examined microscopically. The percentage of macrophage cells (A), lymphocytes (B), neutrophils (C), eosinophils (D), mast cells (E), and epithelial cells (F) were estimated in the total cellular content of BAL and TW samples collected from healthy camels and camels with respiratory diseases. Date is presented as mean \pm standard error of the mean (SEM). There were considered to be differences in mean values when there was a $P$-value of less than 0.05 . 
A)

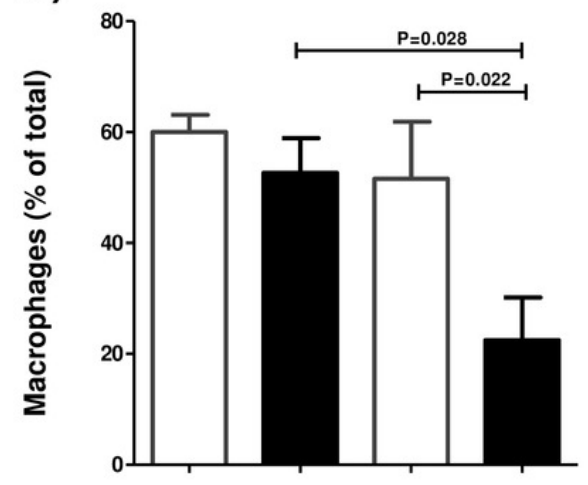

C)

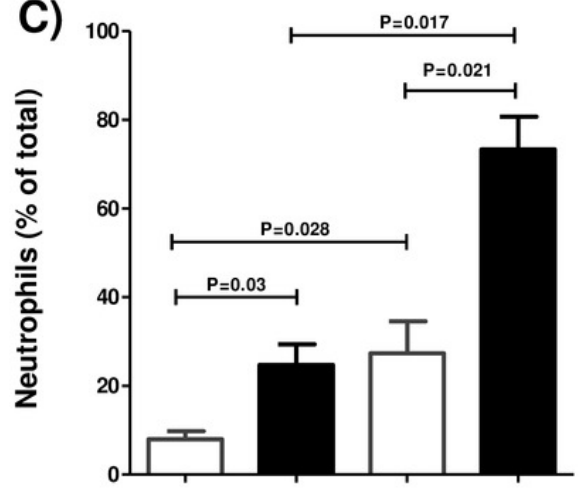

E)

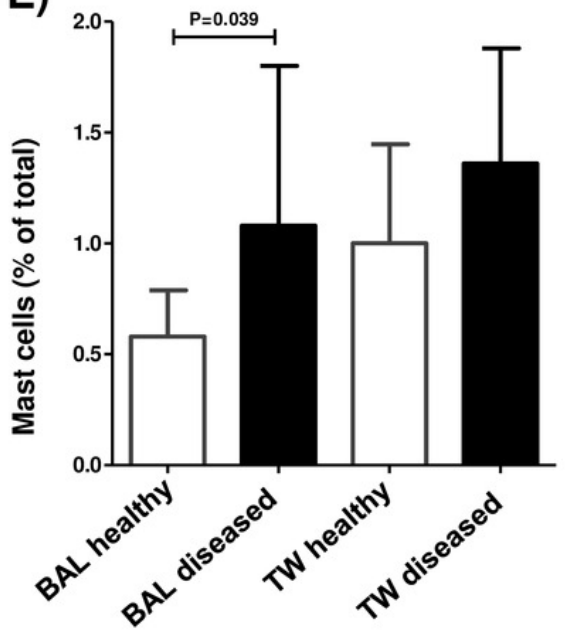

B)

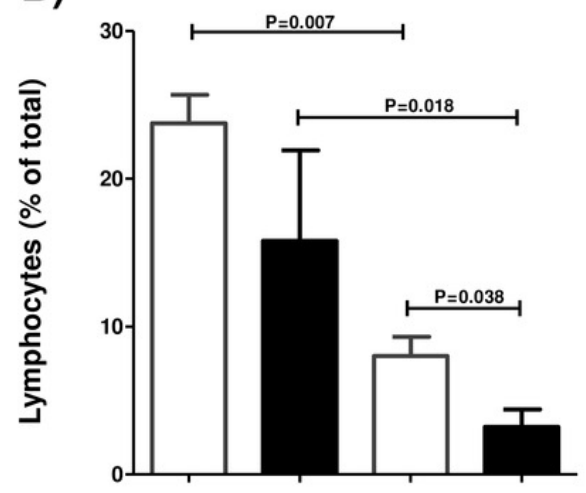

D)

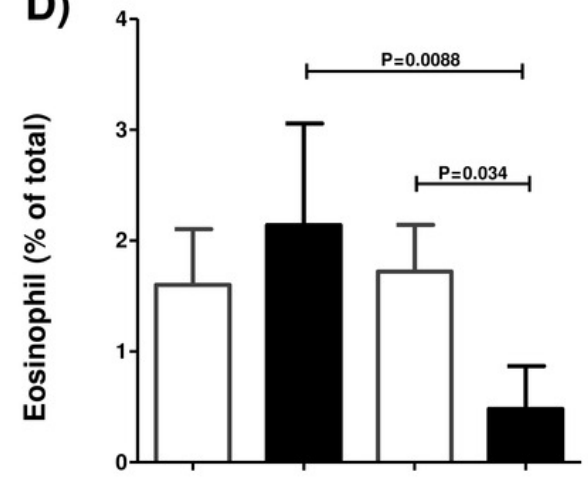

F)

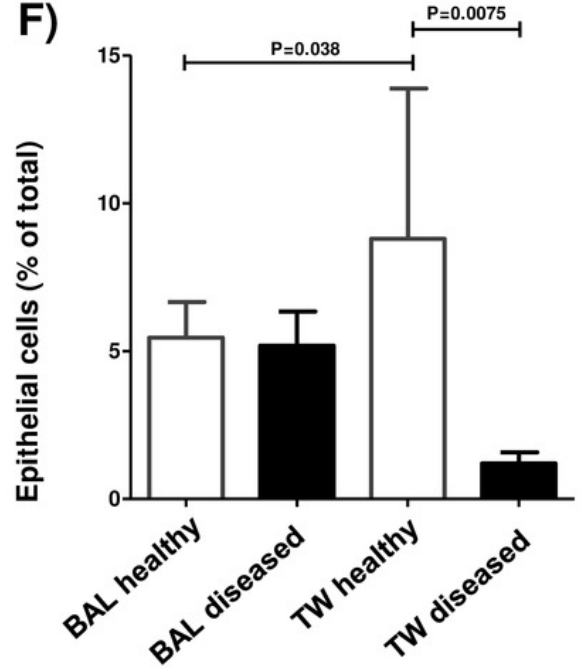


Table $\mathbf{1}$ (on next page)

Detailed scoring system points for respiratory-affected camels 
1 Table 1: Detailed scoring system points for respiratory-affected camels

2
Parameter
Clinical findings

\section{Cough}

\begin{tabular}{ll}
\hline $\mathbf{0}$ & None \\
\hline $\mathbf{1}$ & Rare \\
\hline $\mathbf{2}$ & Daily repeated \\
\hline $\mathbf{3}$ & Spontaneous during clinical examination \\
\hline $\mathbf{D y s p n o e a}$ & \\
\hline $\mathbf{0}$ & No difficulty in respiration \\
\hline $\mathbf{1}$ & Mild visible increase of the abdominal movement at the end of expiratory \\
& phase. \\
\hline $\mathbf{2}$ & A clear abdominal movement during expiration. \\
\hline $\mathbf{3}$ & A difficult abdominal breathing with wide nostrils. \\
\hline $\mathbf{4}$ & High degree of respiratory distress \\
\hline $\mathbf{L}$ &
\end{tabular}

\section{Lung auscultation}

\begin{tabular}{ll}
\hline $\mathbf{0}$ & Physiological (vesicular inspiration) \\
\hline $\mathbf{1}$ & Mild degree of sharpness of inspiratory sounds. \\
\hline $\mathbf{2}$ & Exaggerated inspiratory sounds and quite expiratory sounds. \\
\hline $\mathbf{3}$ & Roughness in both expiratory and tracheal rattle sounds. \\
\hline $\mathbf{4}$ & "Wheezes, Crackles" and or rattle sounds over the lung area. \\
\hline Rectal temperature \\
\hline $\mathbf{0}$ & $<36.5$ \\
\hline $\mathbf{1}$ & $36.7-39$ \\
\hline $\mathbf{2}$ & $39.1-40$ \\
\hline $\mathbf{3}$ & $>40.1$
\end{tabular}




\section{Table 2 (on next page)}

Total and differential cell counts (Mean \pm SEM and range) in TW and BAL fluids from 27 camels ( 9 healthy and 18 affected) 
1 Table. 2: Total and differential cell counts (Mean \pm SEM and range) in TW and BAL fluids from 27 camels

2 (9 healthy and 18 affected).

3

Tracheal Wash (TW)

Bronchoalveolar Lavage Fluid (BAL)

\begin{tabular}{|c|c|c|c|c|c|c|c|c|}
\hline & \multicolumn{2}{|c|}{ Healthy } & \multicolumn{2}{|c|}{ Affected } & \multicolumn{2}{|c|}{ Healthy } & \multicolumn{2}{|c|}{ Affected } \\
\hline & Mean \pm SEM & Range & Mean \pm SEM & Range & Mean \pm SEM & Range & Mean \pm SEM & Range \\
\hline Total cell count & - & - & - & - & $200.4 \pm 39.22$ & $60-440$ & $\begin{array}{c}824 \pm 401.1 * \\
*\end{array}$ & $\begin{array}{l}260- \\
2400\end{array}$ \\
\hline Macrophages $\%$ & $51.60 \pm 10.25$ & $22-72$ & $22.46 \pm 7.69$ & $6-45$ & $60.01 \pm 3.11$ & $46-75$ & $52.66 \pm 4.24$ & $37-66$ \\
\hline Lymphocytes \% & $8.20 \pm 1.3$ & $4-11$ & $3.2 \pm 1.2$ & $1-7$ & $23.74 \pm 1.93$ & $14-35$ & $15.80 \pm 6.11$ & $11-33$ \\
\hline Neutrophils \% & $27.34 \pm 7.21$ & $12-54$ & $73.30 \pm 7.42$ & $51-88$ & $7.95 \pm 1.80$ & $2-19$ & $24.68 \pm 4.67$ & $16-39$ \\
\hline Mast cells \% & $1 \pm 0.44$ & $0-2$ & $1.36 \pm 0.13$ & $0-3$ & $0.58 \pm 0.21$ & $0-2$ & $1.08 \pm 0.72$ & $0-3$ \\
\hline Eosonophils\% & $1.72 \pm 0.42$ & $1-3$ & $0.48 \pm 0.38$ & $0-2$ & $1.6 \pm 0.5$ & $0-4$ & $2.14 \pm 0.92$ & $0-6$ \\
\hline Epithelia cells \% & $8.8 \pm 5.08$ & $2-29$ & $1.2 \pm 0.37$ & $0-2$ & $5.45 \pm 1.2$ & $1-11$ & $5.18 \pm 1.16$ & $1-8$ \\
\hline
\end{tabular}

4

5 


\section{Table 3(on next page)}

Total and differential cell counts (Mean \pm SEM and range) in TW and BAL fluids from 27 camels regarding rectal temperature $(6$ with normal $(<39)$ rectal temperature and 22 with high (>39.1) rectal temperature) healthy and 18 affected). 
1 Table. 3: Total and differential cell counts (Mean \pm SEM and range) in TW and BAL fluids from 27 camels

2 regarding rectal temperature $(6$ with normal $(<39)$ rectal temperature and 22 with high $(>39.1)$ rectal

3 temperature) healthy and 18 affected).

4

\begin{tabular}{|c|c|c|c|c|c|c|c|c|}
\hline & \multicolumn{4}{|c|}{ Tracheal Wash (TW) } & \multicolumn{4}{|c|}{ Bronchoalveolar Lavage Fluid (BAL) } \\
\hline & \multicolumn{2}{|c|}{$\begin{array}{c}\text { Normal rectal } \\
\text { temperature }(<39)\end{array}$} & \multicolumn{2}{|c|}{$\begin{array}{c}\text { High rectal } \\
\text { temperature }(>39,1)\end{array}$} & \multicolumn{2}{|c|}{$\begin{array}{c}\text { Normal rectal } \\
\text { temperature }(<39)\end{array}$} & \multicolumn{2}{|c|}{$\begin{array}{c}\text { High rectal } \\
\text { temperature }(>39,1)\end{array}$} \\
\hline & Mean \pm SEM & Range & Mean \pm SEM & Range & Mean \pm SEM & Range & Mean \pm SEM & Range \\
\hline Total cell count & - & - & - & - & $587 \pm 115.7$ & $60-2250$ & $1653 \pm 235.6^{*}$ & $815-2400$ \\
\hline Macrophages $\%$ & $36.24 \pm 4.55$ & $6-72$ & $17.43 \pm 3.99 *$ & $6-31$ & $56.71 \pm 2.06$ & $37-75$ & $48.58 \pm 4.34$ & $37-65$ \\
\hline Lymphocytes \% & $5.1 \pm 0.82$ & $1-11$ & $4.17 \pm 0.94$ & $1-7$ & $19.93 \pm 2.02$ & $1-35$ & $11.67 \pm 5.19^{*}$ & $1-35$ \\
\hline Neutrophils $\%$ & $51.22 \pm 5.9$ & $12-88$ & $78.83 \pm 3.89 *$ & $62-88$ & $14.76 \pm 1.99$ & $2-36$ & $31.42 \pm 4.33^{*}$ & $17-49$ \\
\hline Mast cells \% & $1.37 \pm 0.21$ & $0-3$ & $1.1 \pm 0.48$ & $0-3$ & $1.17 \pm 0.24$ & $0-3$ & $1.33 \pm 0.61$ & $0-3$ \\
\hline Eosonophils\% & $1.1 \pm 0.22$ & $0-3$ & $0.47 \pm 0.32 *$ & $0-2$ & $1.62 \pm 0.32$ & $0-5$ & $2.34 \pm 1.05^{*}$ & $0-6$ \\
\hline Epithelia cells \% & $4.48 \pm 1.44$ & $0-29$ & $1.33 \pm 0.33 *$ & $0-2$ & $5.48 \pm 0.61$ & $1-11$ & $4.67 \pm 1.28$ & $1-8$ \\
\hline
\end{tabular}

$* \mathrm{P}<0.05$ 